\title{
Organizing Events as a Tool to Develop Marketing Skills - the atUAliza.te Event Case Study
}

\author{
Joaquim Marques', Ana Estima
}

${ }^{1}$ ISCA, University of Aveiro, Portugal, ${ }^{2}$ GOVCOPP, ISCA, University of Aveiro, Portugal.

\begin{abstract}
Marketing education literature is prolific in research dedicated to the best methodologies to provide higher education students with the knowledge as well as the soft and hard skills needed for their future careers as marketing experts. This article presents an experiment developed in a marketing degree, that took place outside the classroom over the last twelve years. The experiment consists of organizing an annual marketing conference coordinated by a team of students who are supervised by a marketing teacher. It is a two-day event that brings together the best speakers from the market and academia targeting both marketing students and professionals. The participation of students as part of the organizing team is voluntary and no assessment is performed by any course of the degree. These students refer to the development of skills such as improving negotiation skills, networking, public speaking skills, organization, planning, team management, conflict management, leadership, time management, among others, as an added value for their careers.
\end{abstract}

Keywords: Events Organization; events Management; marketing education; skills. 


\section{Introduction}

The objective of this paper is to present the event "atUAliza.te - The Marketing Conference" whose creation, evolution and organization is an initiative from marketing students of the University of Aveiro - Portugal. The paper also intends to explore how being part of the organizing team of such initiatives allows students to develop competencies and contribute to their education in the marketing field, as a whole. The paper starts by presenting some literature review about the most important skills to cope with the requirements of the market and how experience-based methodologies such as the organization and management of this type of events can contribute to complement the students' training. The third section is dedicated to describing the main phases of the organization of the event, how the team is organized and works both internally among the team members and externally with all the stakeholders involved in this endeavour, followed by testimonies from students, the role of the teacher, some important facts and numbers and conclusions related to this activity's importance to the students are also presented, in the final part of the paper.

\section{Literature Review}

There is a vast amount of literature on what concerns new methodologies to improve students' skills, namely in the area of marketing. Besides, the incorporation of new and/or different competencies and subjects in the curricula of undergraduate degrees is often suggested. Several authors indicate that this is not enough and, in an increasingly competitive and challenging world, more than just regular teaching is necessary to change teaching/learning paradigms through new methodologies. Such methodologies can help students to increase their personal and professional skills and enhance performance, linking more easily knowledge to its practical applicability and bridge the gap between the academy and the market (Estima \& Duarte, 2016; Pinheiro et al., 2019). The preference for more active methodologies and a more experience-based pedagogy has been growing in recent decades. A growing body of literature has studied and presented examples of this approach (e. g., Granitz \& Koernig, 2011) and defined it as the process by which learning is promoted based on experience (Maher \& Hughner, 2005), developing market and marketing skills and promoting greater student satisfaction (Caza et al., 2015). Forman, (2006) argues that this methodology, when combined with more traditional methodologies, can have an even greater impact on students, developing individual problem-solving skills and innovative challenges.

Besides program degrees covering areas such as event organization, protocol, institutional relations and related subjects, to the best of our knowledge, no one addressed the topic of event organization as a teaching methodology to improve skills in marketing students. The literature shows that the organization and management of events "requires particular skills, knowledge, and competencies" (Perry et al., 2011, p. 85), including vision, adaptability, 
leadership skills, high organization skills, marketing, communication, commitment, strategic planning, accountability and people management (Bowdin et al., 2006; Padron \& Stone, 2019; Perry et al., 2011). The important skills that result from this kind of experience-based activity could be an excellent approach to develop the main skills required by 21 st-century marketers (Coelho, 2019; Schlee \& Harich, 2010).

This paper presents an overview of the "atUAliza.te - The Marketing Conferences" event creation, evolution and organization and intends also to explore how participating in the organization and management of this type of activities allow students to develop competences and contribute to their marketing education.

\section{Case Study}

This section presents atUAliza.te case study, starting by sharing the history and describing all the activities involved in each of the phases of the event, including the competences that the marketing students develop and acquire. In the end, some important facts and numbers are highlighted to demonstrate the importance and magnitude of this activity.

\subsection{History and Scope}

Created in 2009 under the insignia atUAliza.te (the word in Portuguese means something like "update yourself" and the capital letters UA are the initials of the University of Aveiro), this marketing conference reflects the initiative of the students who, over the years, have worked together to position the event at a national level. The event is held annually and brings together leading Marketing professionals and keynote speakers that represent brands who stand out for their innovation, creativity, quality and who are inspiring and stimulating examples for the audience. Over the years it has become a must-attend event for students, entrepreneurs, and professionals eager to explore new trends in the area, from the most varied sectors. One of the main purposes of the organization team is to create a moment for training, knowledge update, networking and to promote the proximity between the University and the Market. Each year the main subject is chosen and the invited speakers from different market sectors ranging from retail, services, industry, fashion, automotive, etc, are contacted. The topic of the conference changes annually to match the most recent topics and market trends. Past topics have been related to branding, personal branding, content marketing, creative thinking, luxury marketing, digital marketing, among many others. In 2014, for the first time, the event welcomed an international speaker and, since then, many other international brands have been represented. This year, the event will have its twelfth edition, which was not held in 2020 due to the pandemic situation. 


\subsection{The event}

In this section, all the organizational process is presented, based on the three phases of the event planning process - Pre-event; (hosting) Event and Post-event. All the routines and decisions are detailed, and, for each phase, a list of the potential competencies acquired and a small testimony representing the student's team is presented to illustrate the experience in first-person.

\subsubsection{Pre-Event}

This is the first step of the process, and the main objective is the constitution of the team. It starts with the selection of the students who will be responsible for the team and assume the Management of the conference program. Usually, some students from the previous year are already identified to take on this role and responsibility in the following year given their performance and work. Other teams related to Communication and Design; Sponsorship and Finance and Staff are then formed. Each team has its specific functions according to the description below.

- Management of the Program - This is also the team responsible for the whole event, and the main responsibilities are: (i) selecting the other team leaders; (ii) coordinating the other teams in weekly meetings; (iii) proposing the theme for the current edition and submitting it to the group of leaders; and (iv) selecting, contacting and inviting the speakers according to the theme of the event. This team has also the responsibility to report to the general coordinator (i.e., the teacher indicated to supervise the whole group of students). The main skills developed are Leadership, Resilience, Planning, Coordination, Negotiation, Argumentation.

- Communication and Design: This team is responsible for the development of the event's entire internal and external communication policy, as well as the development of all graphic/digital communication support (examples of this materials can be seen on the page of the event AtUAliza.Te, 2021). Students in this team are also responsible for the creation, development and managing of the event's social networks and website. On the day of the event, they are responsible for the live news of all the communications including live social media management. The main skills developed are design, creativity, flexibility and, communication.

- Sponsorship and Financial: this team is in charge of searching and selecting the event sponsors, presenting the sponsorship dossier (developed by the communications team) that describes the different types of sponsorship and respective benefits offered. The same applies to the event partners whose participation, involvement and continuity over time have been growing (i.e., the main sponsors). They are also responsible for the management of the online tickets 
store and the revenue of the event, processing all the income and expenses and managing all the processual documents. The main skills developed are leadership, resilience, argumentation, flexibility, communication and, negotiation.

- Staff: this team complements and supports the other teams, assuming a character of greater importance on the day of the event, forming all the human resources support to the event, involving the reception, routing and information to the participants. Each team member has a specific role on the day of the event, such as check-in, coffee break management or room assistant. The main skills developed are leadership, resilience, flexibility and, communication.

\subsubsection{Event Hosting}

The event takes place over two consecutive days, in the Auditorium of the University of Aveiro. The speakers, partners, sponsors and participants are welcomed and all the tasks necessary for the smooth running of the event are carried out. This is normally the most stressful period since it is the result of all the work developed for over ten months. It is also the moment to verify the quality of all the work done. The main skills developed are Management of contingencies, conflict management, time management, leadership, stress management, people management.

\subsubsection{Post-Event - Evaluation and follow-up}

This is the moment to perform the evaluation and follow-up of the event. The event is evaluated by the organizing team, the speakers, and the partners and sponsors. The participants' evaluation is also collected at the end of the event through a questionnaire. These data are then communicated to those directly involved in the event (i.e., speakers, sponsors and partners), and to the institutional stakeholders using a specific dossier.

Besides this self-assessment exercise, at the closing stage, the potential leaders for next year's edition are identified and invited to start thinking and planning the event. This identification is based on the performance of the elements of the team during all the phases of the event, taking into account their proven experience and demonstrated leadership in different areas. The main skills developed are the ability to self-evaluate, manage expectations, capacity for analysis and reflection and communication.

\subsubsection{Student's Testimonies}

Over the years, as teachers, we followed students and their growing process. Many students show a clear evolution and acquire a very different vision of their education process after participating in the event. As a way of documenting this reality, we selected three testimonies from students who started their participation in their first academic year as regular Staff members and were then selected to participate as team leaders in the following editions. 
"For many of us, atUAliza.te was our first challenge - our first practical case, lived as a team, in the first person, on a more professional rather than academic setting. It was our first and closest contact with the labour market - it was our first challenge to develop skills in communication, planning, negotiation, strategy, ... and MARKETING!'”Alumni 1

"For me, atUAliza.te is, and always will be, the reason for my professional success. It was the event that gave me my first job in marketing and has been directing me on the right path for building my future. The developed networking, the daily challenges to overcome and the team's leadership make each participant emerge richer from this project." Alumni 2

"From atUAliza.te, I took a huge amount of learning and certainties that all those involved in the events will have a bright future waiting for them based on the leadership, planning and negotiation skills developed." Alumni 3

\subsubsection{Role of the Teacher}

The teacher in charge has the fundamental role of coordinating the whole team and to provide the event with a unique identity. He also officially represents the University in the relationship with speakers, guests, sponsors and partners. He assumes the responsibility of choosing the program managers, delegating to them the task of recruiting the remaining staff (normally the team as around thirty students). These recruited elements come from different courses and academic years. Moreover, as already mentioned, the team is mainly constituted by marketing students. These teams always report to the teacher in charge and need his agreement when making key decisions.

\subsubsection{Facts and Numbers}

Among many other things, there are some facts and numbers that demonstrate the relevance of the event, which we would like to highlight:

- $\quad$ Sponsors - From the first year the number increased from 4 to 30, demonstrating the interest of the event for the companies;

- $\quad$ Speakers - Throughout the 12 editions we had more than 230 speakers, about 20 per edition;

- Conference participants - We went from about 50 participants in the first to around 750 participants per edition;

- Students - Throughout all the editions we have had a total of over 400 students participating as part of the organizing team (around 30 per year)

- $\quad$ Partners - Over the years we have had partnerships with the University of Aveiro and ISCA-UA as internal partners, RFM (a national radio) as the communication partner, and specialized national and local press; 
- $\quad$ Budget - The event's average budget is currently around $€ 35.000$;

- Recognition - The event has been recognised as the best national marketing conference and one of the best in management, according to specialized magazines; several other universities organise study trips for their students to attend the conference every year; employers in the region and nationally recognise the skills of those involved in these conferences and today we can state that several students have obtained their first professional experience as a result of these conferences;

- The event is operated as an extra-curricular activity with voluntary participation and is not linked to the assessment of any curricular unit.

\section{Conclusions}

As can be noticed on the page of the event (AtUAliza.Te, 2021), this initiative has been growing in quality, popularity and importance over the past twelve years. It is now positioned in Portugal as one of the best national marketing conferences and is particularly a reference for marketing students but also students from other related areas such as design, advertising, management, international relations, among others. This perceived quality relates to aspects already mentioned in section 2.2.6. However, we would like to highlight that as the event became more notorious, it started to become easier to attract more sponsors and, consequently allowed us to invite other relevant keynote speakers (e.g., from international brands). Although not explored in this article, the participants' evaluation is also collected at the end of the event through a questionnaire, enabling us to measure the evolution of the event over time.

In this case study, rather than presenting a narrative of what we have developed with the students in recent years, we wanted to demonstrate how it is possible to develop technical and soft skills and create an institutional culture and a huge sense of belonging on students, with the organisation and management of an event. As teachers, there are some aspects that we would like to share beyond what was explicit in the case study. Students who participate in the event team develop a new sense of responsibility, identify themselves with the event, create a sense of achievement, increase their interpersonal skills and significantly increase their network.

As a school with other degrees in accounting and finance, the team recently decided to allow these students to also participate in the organization of the event, particularly in the budget team. This bond has also been very interesting to observe, as it was rare to see it in other more formal activities.

Despite being a very demanding activity, it is also easy to transpose to other contexts and colleagues from other areas besides marketing can use this model to benefit universities and 
students and their relationship with the industry. Moreover, the authors strongly believe that organizing such events during the graduation period, provides students with something that goes far beyond what they could learn inside the classroom.

In the future, it would be interesting to discuss the implementation of this conference concerning other (marketing) students' conferences - either in Portugal or even in a broader international context (e g. European, global). This would allow us to deepen the conclusions of this study and compare the results, particularly regarding the skills acquired with this type of activity.

\section{References}

atUAliza.te. (2021). http://www.atualizate.pt/

Bowdin, G., O’Toole, W., Allen, J., Harris, R., \& McDonnell, I. (2006). Events management. Routledge.

Caza, A., Brower, H. H., \& Wayne, J. H. (2015). Effects of a holistic, experiential curriculum on business students' satisfaction and career confidence. International Journal of Management Education, 13(1), 75-83. doi: 10.1016/j.ijme.2015.01.006

Coelho, A. (2019). Marketing: Looking for a Place in the 21st Century. In S. Pinheiro, M. M., Estima, A., \& Marques (Ed.), Evaluating the Gaps and Intersections Between Marketing Education and the Marketing Profession (pp. 34-37). IGI Global.

Estima, A., \& Duarte, P. (2016). The Mismatch between Undergraduate Marketing Education and Employers' Requirements in Portugal. In Global Perspectives on Contemporary Marketing Education (pp. 18-36). IGI Global.

Forman, H. (2006). Participative case studies: Integrating case writing and a traditional case study approach in a marketing context. Journal of Marketing Education, 28(2), 106-113. doi: $10.1177 / 0273475306288398$

Granitz, N., \& Koernig, S. K. (2011). Web 2.0 and marketing education: Explanations and experiential applications. Journal of Marketing Education, 33(1), 57-72. doi: $10.1177 / 0273475310392539$

Maher, J. K., \& Hughner, R. S. (2005). Experiential Marketing Projects: Student Perceptions of Live Case and Simulation Methods. Journal for Advancement of Marketing Education, 7 (Hamer 2000), 1-10. http://www.mmaglobal.org/publications/JAME/JAMEIssues/JAME-2005-Vol07-Issue1/JAME-2005-Vol07-Issue1-Maher-Hughner-pp110.pdf

Padron, T. C., \& Stone, M. J. (2019). Leadership Skills in Event Management Courses. Event Management, 23(6), 927-937. doi: 10.3727/152599518X15403853721321

Perry, M., Foley, P., \& Rumpf, P. (2011). Events Management: An Emerging Challenge in Australian Higher Education. Festival Management and Event Tourism, 4(3), 85-93. doi: $10.3727 / 106527096792195326$

Pinheiro, M. M., Estima, A., \& Marques, S. (2019). Evaluating the Gaps and Intersections Between Marketing Education and the Marketing Profession. IGI Global. 
Schlee, R. P., \& Harich, K. R. (2010). Knowledge and skill requirements for marketing jobs in the 21st century. Journal of Marketing Education, 32(3), 341-352. doi: $10.1177 / 0273475310380881$ 